\title{
Creating E-Courses for Learning the CAD Basics
}

\author{
Sergei A. Burtsev ${ }^{1}$ and Bronislav B. Novitskiy ${ }^{1 *}$ \\ ${ }^{1}$ Bauman Moscow State Technical University, 2nd Baumanskaya str., 5/1, 105005, Moscow, Russia.
}

\begin{abstract}
Article is devoted to the peculiarities of creating an electronic course on learning the basics of three-dimensional design of wind power plant elements using modern software systems. The iSpring Suite program was chosen as a course development tool. It has support for the SCORM 2004 format and extensive integration with office suites. In order to minimize problems with working in various distance learning systems, the course was divided into nine modules. The first module is dedicated to the basics of wind energy. The second module provides an overview of existing CAD programs. The third and fourth modules are dedicated to 2dimensional design. The fifth and sixth modules introduce commands for creating 3-dimensional parts from both other parts and 2-dimensional sketches. Module 7 is devoted to algorithms for creating assemblies from existing 3-dimensional parts. Module 8 and 9 represent the implementation of the multiplier/reducer Assembly algorithm from ready-made 3dimensional parts that are present in the course resources.
\end{abstract}

\section{Introduction}

\subsection{General provisions in wind energy}

Today, renewable energy is increasingly included in the global energy sector. At the same time, the most significant parts (in terms of capacity input volumes) are solar and wind energy [1].

Large-Scale wind farms (LSWF) have become quite widespread in the last 10-15 years. At the same time, several main problems of wind energy development are known: environmental aspects, problems in choosing places for wind farms, problems of the influence of wind power generating capacities on energy systems, etc.

All this, together with a slow decrease in the cost of generating electricity at wind power stations, leads to a slowdown in the growth of the share of wind energy in the total generation balance.

\footnotetext{
${ }^{*}$ Corresponding author: novitskiybronislav@bmstu.ru
} 


\subsection{Problems when choosing places for wind farms}

From a technical point of view for successful operation of modern wind turbines should be placed to provide sustainable wind field at the level of 9-12 m/s. Thus the deviation of the wind speed up and down is not desirable.

Figure 1 shows a map of the average annual energy density of wind flow for a height of $100 \mathrm{~m}$ (typical height of the LSWF tower), constructed from data [2]. If one analyzes it, it can be seen that in most of Russia the average annual energy density of wind flow does not exceed $300 \mathrm{~W} / \mathrm{m}^{2}$ (approximately corresponds to $8 \mathrm{~m} / \mathrm{c}$ at an altitude of $100 \mathrm{~m}$ ). The exception is the sea coasts and the steppe zone to the North of the Black and Caspian sea.

The discreteness of the data presented in [2] is not a problem. Using the method [3], even if the initial meteorological data is insufficient to estimate the wind energy potential, one can use the Weibull function to obtain a continuous field.

For most modern LSWF, the nominal wind speed is from 9 to $12 \mathrm{~m} / \mathrm{s}$ (zones 440-680 and $680-1350 \mathrm{~W} / \mathrm{m}^{2}$ in figure 1 [2]) and such regions in Russia are mainly concentrated in the far East and the Arctic coast. That is, they belong to zones with complex climatic conditions that lead to additional problems during operation (hurricane winds, icing problems of blades, etc.).

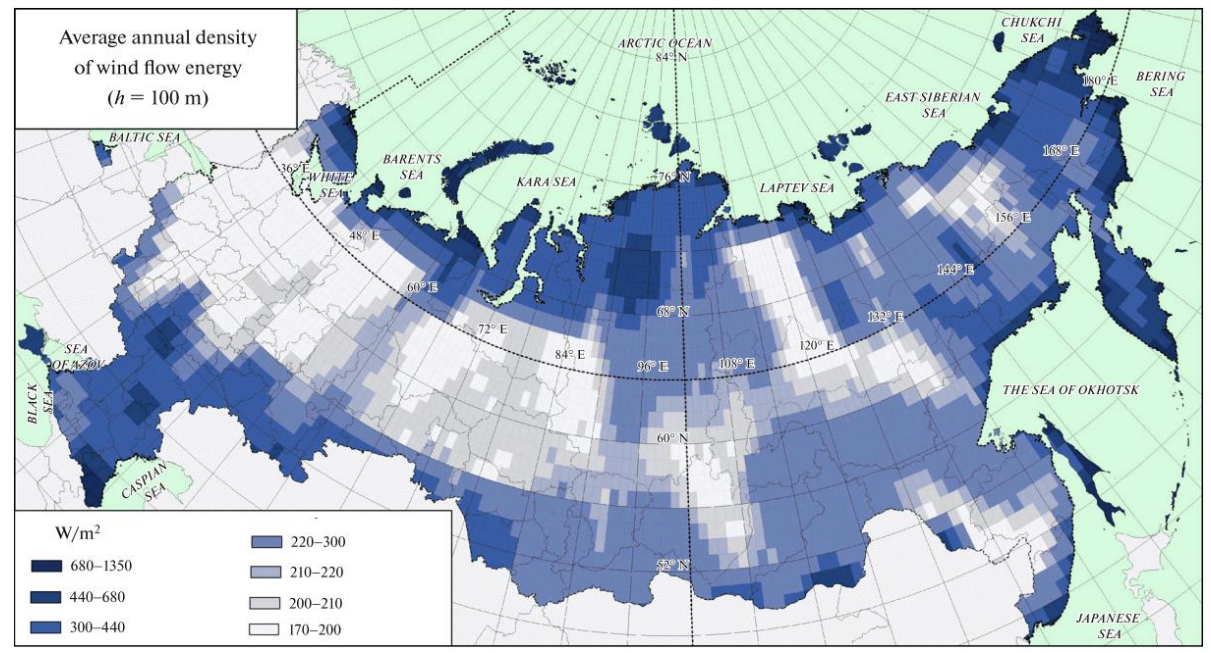

Fig. 1. Average annual energy density of wind flow $\left(\mathrm{W} / \mathrm{m}^{2}\right)[2]$.

At the same time, there is a significant difference between zones with an average speed of 9 and $12 \mathrm{~m} / \mathrm{s}$. LSWF Power with a horizontal axis of rotation (Horizontal-Axis Wind Turbine - HAWT) with a nominal speed of $12 \mathrm{~m} / \mathrm{s}$ at a speed of $9 \mathrm{~m} / \mathrm{s}$ will be low (depending on the manufacturer, it will be from 35 to $45 \%$ of the rated power) [4].

Currently, there are trying to use the offshore zone of the seas (HAWT offshore) to accommodate the LSWF [5]. The environmental and economic analysis of the costs and benefits of offshore wind energy [6] has shown that this is also not a universal solution. As well as the transition to an improved LSWF design [7] or to a Vertical-Axis Wind Turbine (VAWT) [8].

But these measures can significantly reduce the area of wind farms. It is known that the distances between neighboring HAWTS must be at least 3 rotor diameters in the transverse direction and at least 10 rotor diameters downstream in the wind direction [9]. When the wind direction is variable, this leads to a specific power of about $2-3 \mathrm{~W} / \mathrm{m}^{2}$ [10], calculated 
for the total area of the wind farm. Switching to VAWT- based wind farms can raise this value to the level of $30 \mathrm{~W} / \mathrm{m}^{2}$ [10].

\subsection{Environmental problems of wind power plants}

It is known that wind power plants have an impact on the population and the environment [11]. Negative factors when using the most popular HAWT are low- frequency vibrations, noise, rapid movement of the blades, etc. at the same time, researchers note both the impact on natural ecosystems in general [12], and harmful effects on specific biological species: bats [13], golden eagles [14], etc.

In addition, negative impacts may not appear immediately, but accumulate in the surrounding ecological system, resulting in cumulative consequences [15]. To reduce the harmful effects on environmental systems, additional measures must be taken to reduce noise and vibration. It can be:

- use of composite materials with special properties (for vibration damping) instead of monolithic structural materials;

- covering the surface of the blades with a special relief ( types of surface relief that reduce aerodynamic drag and, consequently, noise in certain flow modes, see for example [16]);

- more accurate selection and diagnostics of bearings [17] to reduce vibration levels;

- correct determination of the dynamic stability of the blades under external excitation [18] to reduce noise and vibration;

- modeling of autorotation modes of LSWF rotors [19] to reduce the negative impact, etc.

\subsection{Interaction with energy networks}

It is known that the increasing share of energy generation using LSWF and the inclusion of its in integrated energy systems (Integrated Energy Systems - IES) creates problems for the normal operation of these IES.

or normal operation of the IES, it is necessary to determine the maximum power level of the LSWF that can be integrated into the IES without compromising its reliability and perform a correct assessment of the potential risk if the generation of electricity on the LSWF goes beyond the established uncertainty sets [20]. This problem is usually solved by creating reserve-generating capacities that use hydrocarbon fuel (piston and gas turbine power plants), using systems of Smart Grid energy and potential storage.

Smart Grid technologies allow you to respond to constant changes in energy production by implementing flexible and adaptive strategies for managing and distributing active and reactive power [21].

\section{E-learning course}

\subsection{Technic features}

Currently, there are many distance learning systems (DLS) for remote learning: Moodle, eLearning Server 4G, ilearn-ing Oracle, Sakai, SABA, WebTutor iSpring, and others [22]. They have different functionality, but they support the most common e-learning course formats (AICC, SCORM, and IMS). From the point of view of minimization of problems when integrating electronic learning courses (ELC) into existing databases [23], the SCORM 2004 format was chosen for the courses. 
Creating an electronic training course on CAD is not a trivial task [24], since there are problems with the integration of algorithms for construction/calculations in various programs. This is most effectively done using the depicting algorithm of actions, accompanied by a video sequence showing the features of human interaction with program interfaces. This is especially true because all CAD systems are similar, but have different names for the same commands (the "pull" command in Siemens NX is equivalent to "Push" in T-FLEX CAD). Therefore, you need to use specialized ELC development tools. The most well-known development tools are: Adobe Captivate, CourseLab, eXeLearning, iSpring Suite, and Articulate Studio. All of the above programs have support for SCORM 2004 and have standard templates for creating ELC. ISpring Suite was chosen as a development tool, as the most convenient software package that is fully integrated into MS PowerPoint, thereby significantly reducing the time to learn a new program and allowing you to fully focus on creating an ELC. ISpring is also a domestic (Russian) development, which significantly increases the speed of "feedback" with developers to solve technical problems. In addition, iSpring has built-in functions for capturing a video sequence from the screen (see Fig. 2) and the ability to preview the e-course on various types of devices (including mobile).

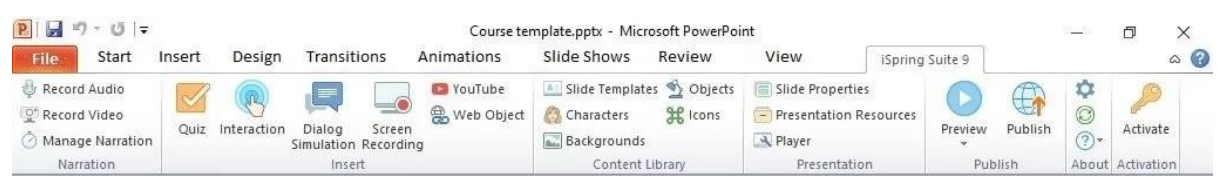

Fig. 2. ISpring control panel integrated in MS PowerPoint.

The preview allows you to test the created electronic course without uploading it to the DLS, reducing time and resource costs (it does not require a separate server or a stable high-speed Internet connection).

\subsection{Course structure}

When creating this ELC, you must understand that course participants can work in any CAD, not just T-FLEX CAD. Therefore, due to the lack of feedback from the audience, it is necessary to tell immediately about the most common existing CAD systems, since knowledge of different CAD systems and understanding of algorithms for building parts and assemblies is a fundamental skill for a highly qualified engineer [25].

The e-learning course is divided into nine modules. All of them are made in the same style (see Fig. 3). At the bottom is the control panel that allows you to listen to the slide again or go to the next one by pressing the "next" key. The right side of the screen contains content that makes it easier to navigate the entire course. Each slide has a voice guide that complements the graphic information. At the end of each mode, there is a test part allowing consolidate the acquired knowledge. To pass the module successfully, you must answer at least $80 \%$ of the questions correctly. 


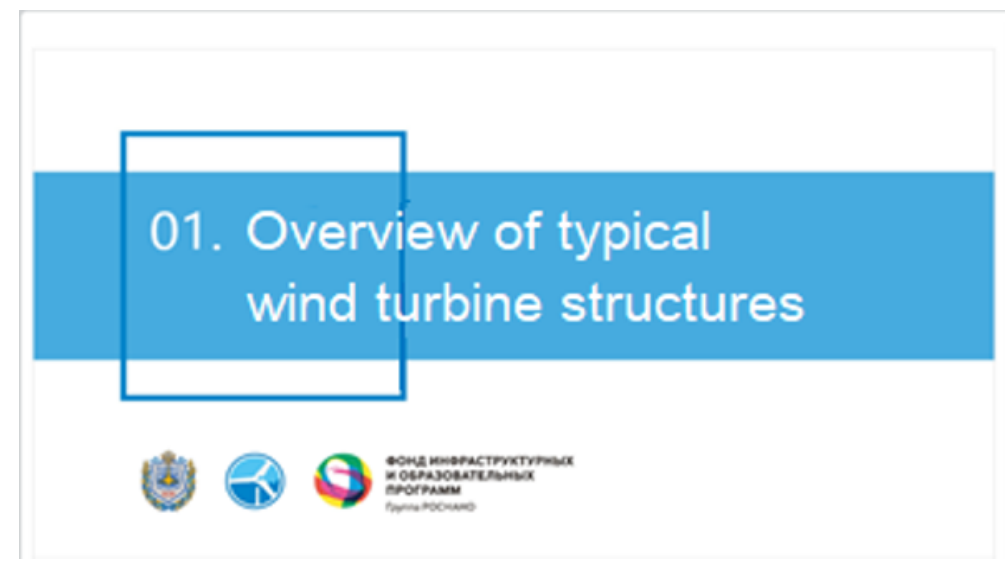

Fig. 3 General ELC style.

The first module is called "An overview of the typical designs of wind turbines". It presents the basics of wind generation and existing types of wind generators, their design differences, advantages and disadvantages. In this module, the question-answer interactivity is widely used, which is a drop-down explanation for the topic under consideration (see Fig. $3)$.

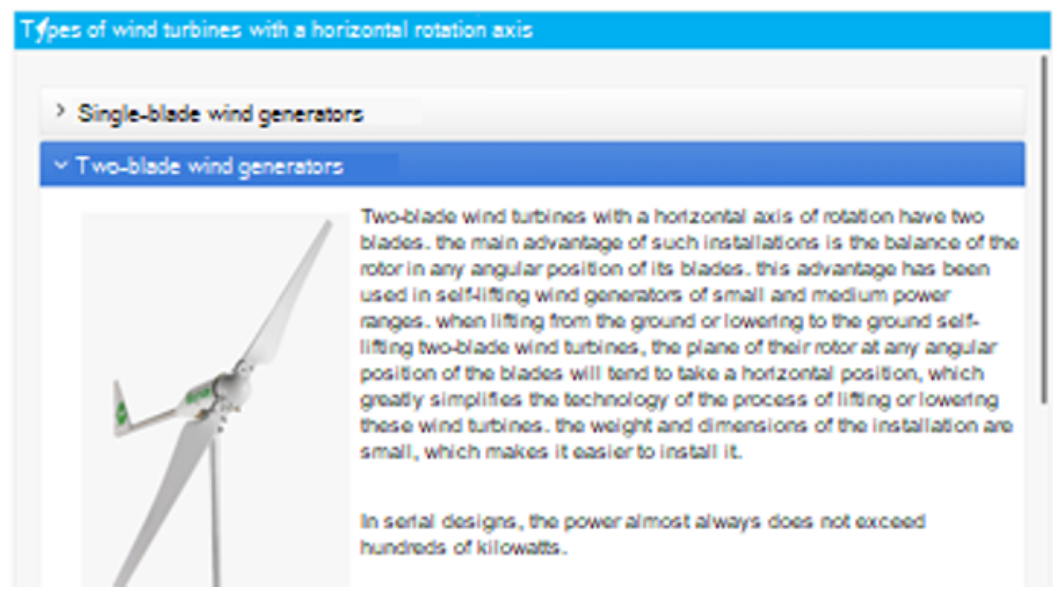

Fig. 4. Typical interactivity "question-answer".

The implementation of this interactivity and the like is carried out through the isuite tool (iSpring Visuals) (see Fig. 5). All interactivity is divided into types: process, annotation, hierarchy, and catalog. Each type has two-five options. 


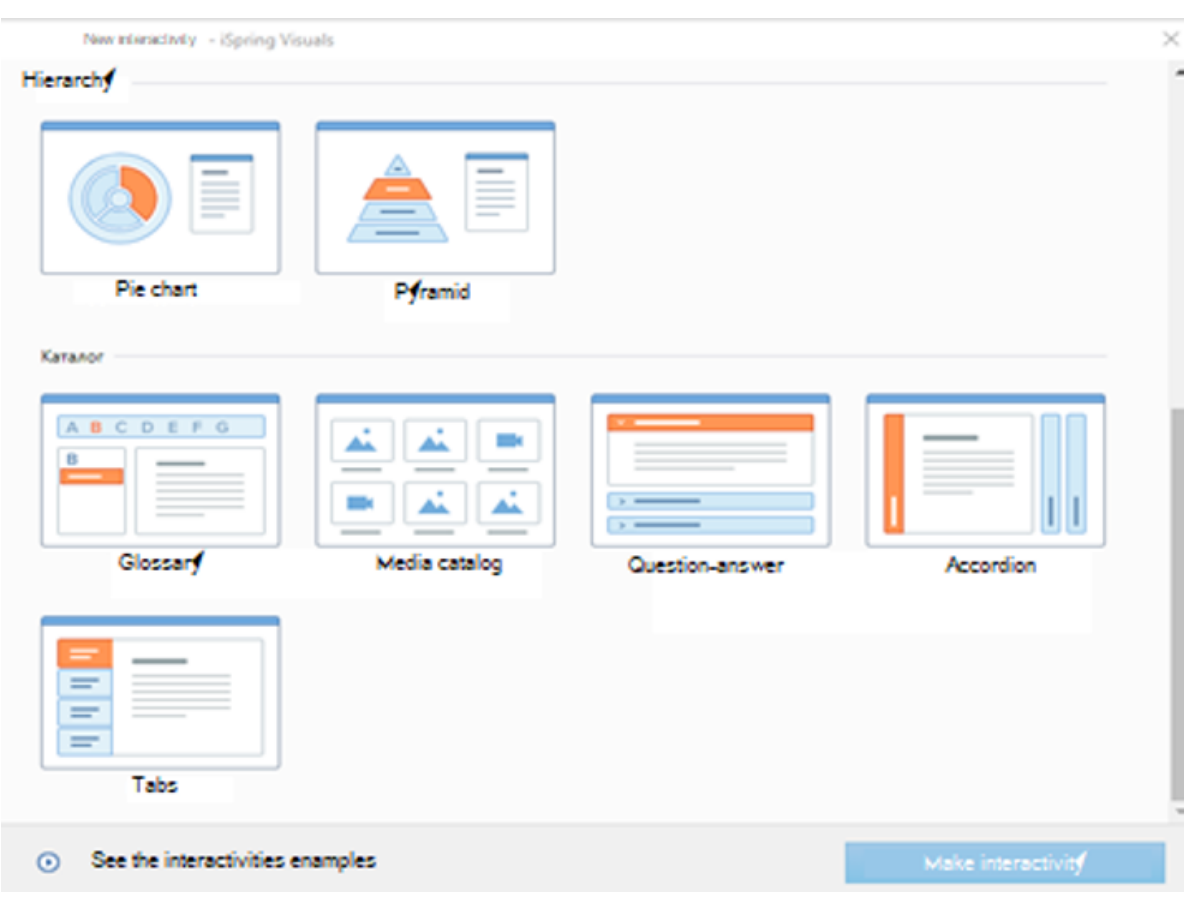

Fig. 5. The model of interactivity.

The second module is called "Basic CAD systems" and talks about existing CAD systems, showing their hierarchy (see Fig. 6). All CAD systems are classified into three levels: beginner, advanced, and professional. This module is an introductory one before starting to study T-FLEX CAD, but it reveals the basic algorithm for designing a 3dimensional part.

This is followed by the topic "2D design in T-FLEX CAD", which is divided into two modules of the same duration. During preliminary testing, it was found that when ELC ( especially rich in video fragments) was passed to The webtutor deployed in DLS, there were freezes that prevented further playback of the content. Especially often these problems occurred when there was a weak Internet channel. Experimentally, it was found that problems with video and audio playback stop when the SCORM format is less than 350 megabytes. Therefore, some themes were divided into 2 modules, which allowed to unload the Internet channel, the DLS server and improve performance.

Module "2D design in T-FLEX CAD. Part 1." shows the program interface and features of 2-dimensional design using "wireframe" and "classic" methods of drawing sketches. Simply listening to an e-course does not allow you to fully develop your design skills. This is why the course provides a link to the free training version of T-FLEX CAD and suggests that after installing the program, you should run the EQ parallel, but repeat the tasks in the training version of the program on the second monitor. For these purposes, the course has integrated "resources", namely links to ready-made tasks that can be downloaded by clicking on the "Resources" button at the top (see Fig. 7). There is not only a drawing of the fitting and shaft, but also a reference to GOST Standards for key and slot connections. In addition, the course is integrated with links to the guidelines for the implementation of connections of details of cars available in the electronic library BMSTU. 


\section{Basic CAD}

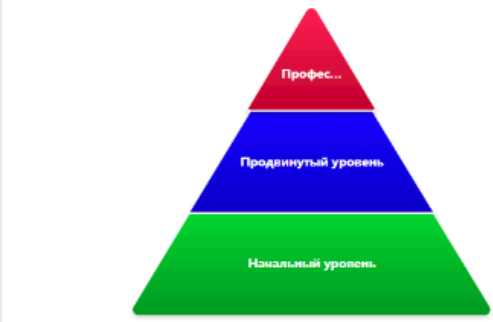

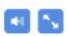

\section{Professional level}

Complex 3D solid-state and surface modeling with a wide range of special modules, libraries, analysis tools, project management, development of control programs for $\mathrm{CNC}$ equipment , the ability to design drawings, etc.

Representatives:

Siemens NX

Dassault Systems Catia

PTC CREO

Fig. 6. Hierarchy of the CAD systems.

Figure 7 shows an interactivity of the "timeline" type, where operations with explanations are gradually interleaved, allowing completely repeating a similar construction on their own in the training version of the program. After performing some complex operations, there is a video clip on a separate slide that repeats the previously written algorithm for building certain elements. This approach has proven itself well in terms of developing design skills in various CAD systems. Because often when updating a program, the icons of some operations may change, but the algorithm and their location will remain unchanged, which is illustrated by the video series.

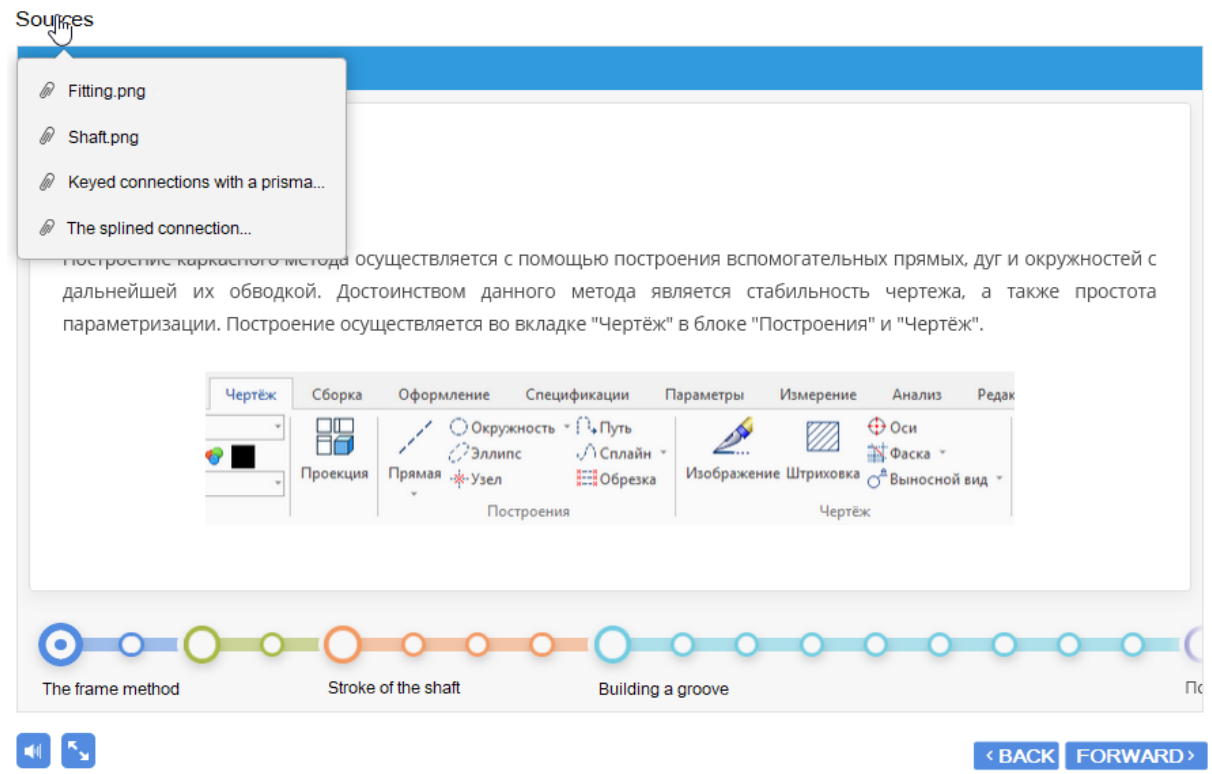

Fig. 7. Location of resources in ELC. 
In order to facilitate the perception of the video sequence, dynamic prompts are integrated into it (see Fig. 8). Hints shows the place where the mouse was pressed and which keys were pressed on the keyboard. The movement of the mouse cursor is highlighted in a yellow circle. In order not to clutter the listener with information in the video sequences, there is no audio accompaniment. All videos are up to 5 minutes long and have their own control panel that allows you to stop playback or repeat the video again. It is assumed that the audience, after viewing part of the video, will put it on pause and perform similar builds in the training version of T-FLEX CAD.

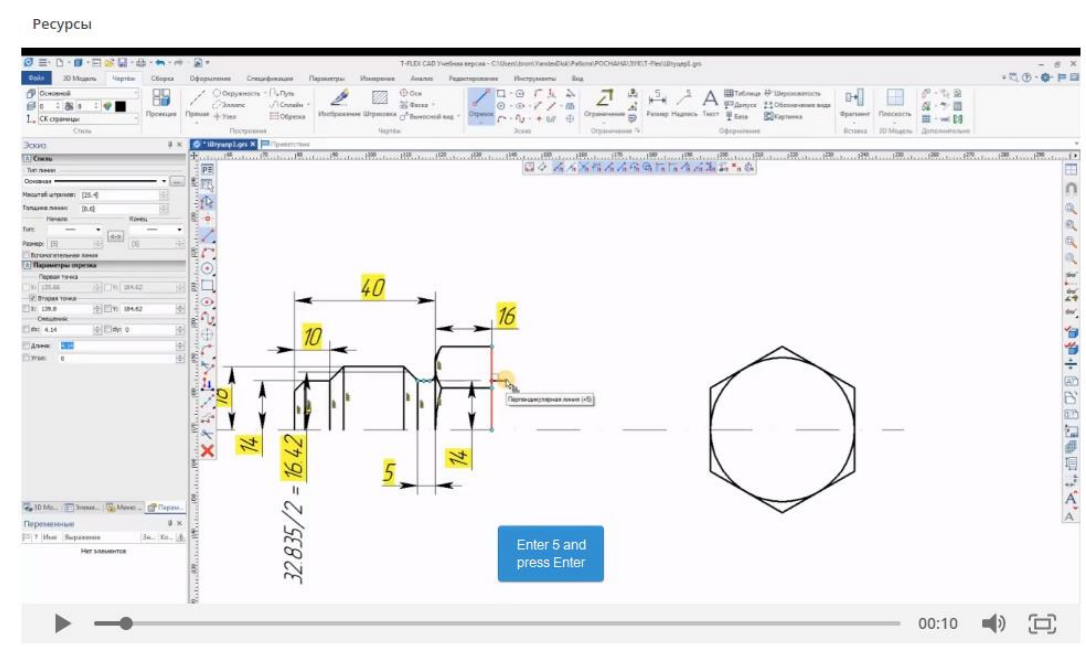

Fig. 8. Hints in the video sequence (blue rectangle).

An important part of securing knowledge is conducting test work. However, it does not make sense to memorize the names of commands in CAD systems, since each program can have its own name. Therefore, in order to consolidate knowledge in the test part, the emphasis was placed on building algorithms. Figure 9 suggests choosing the correct sequence of operations for building the shape.

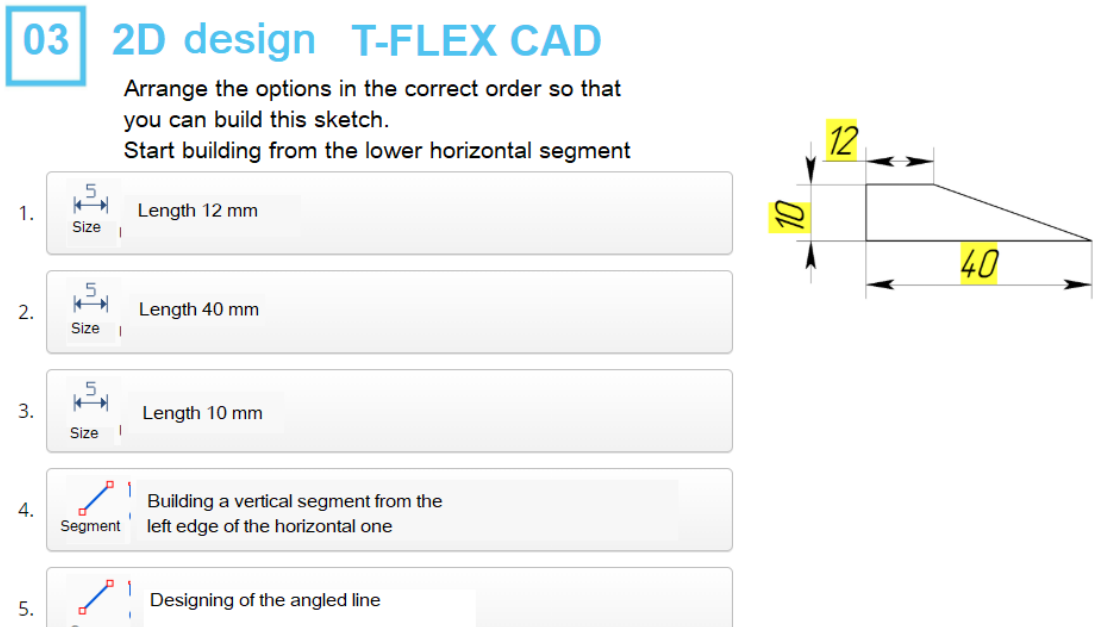

Fig. 9. Task for the sequence of operations. 
Figure 10 shows the "drag and drop" task, where the listener needs to drag the necessary operations from the command bar to the inside of the shape to be built.

\section{2D design T-FLEX CAD}

What operations are needed to build
this shape using the "classic" method?

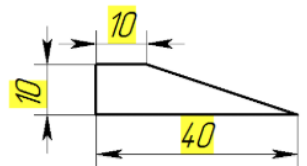

Drag the required operations inside the shape by holding the left mouse button

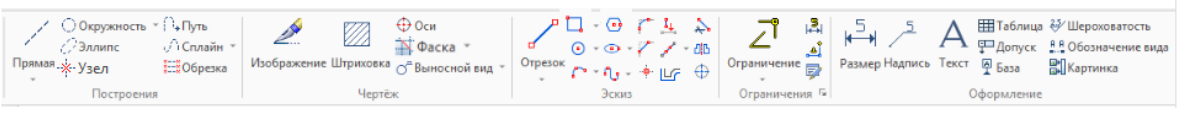

Fig. 10. "Drag and drop" task.

Modules 5 and 6 are dedicated to "3D Modeling in T-FLEX CAD". They provide an overview of all the main commands for building not only solid parts, but also shells. The "3D Modeling" resources contain nine three -dimensional 3D model blanks (see Fig. 11), with the help of which it is proposed to work out the main operations considered in the course. For example, the part "Blade_1" (see Fig. 12) is a set of sketches of blade profiles (sections). Each section is made according to its own law of profiling, the blade is obtained if all sections are connected by a certain surface. In this way, one can build a wind generator, using this method one can build any blades (including aircraft fans) and blades of gas turbine engines and installations. The "Radiator" part allowing work out the using of "array" operation skill, and the "Fan" method of connecting the fan blade to the bushing with different rounding radiuses.

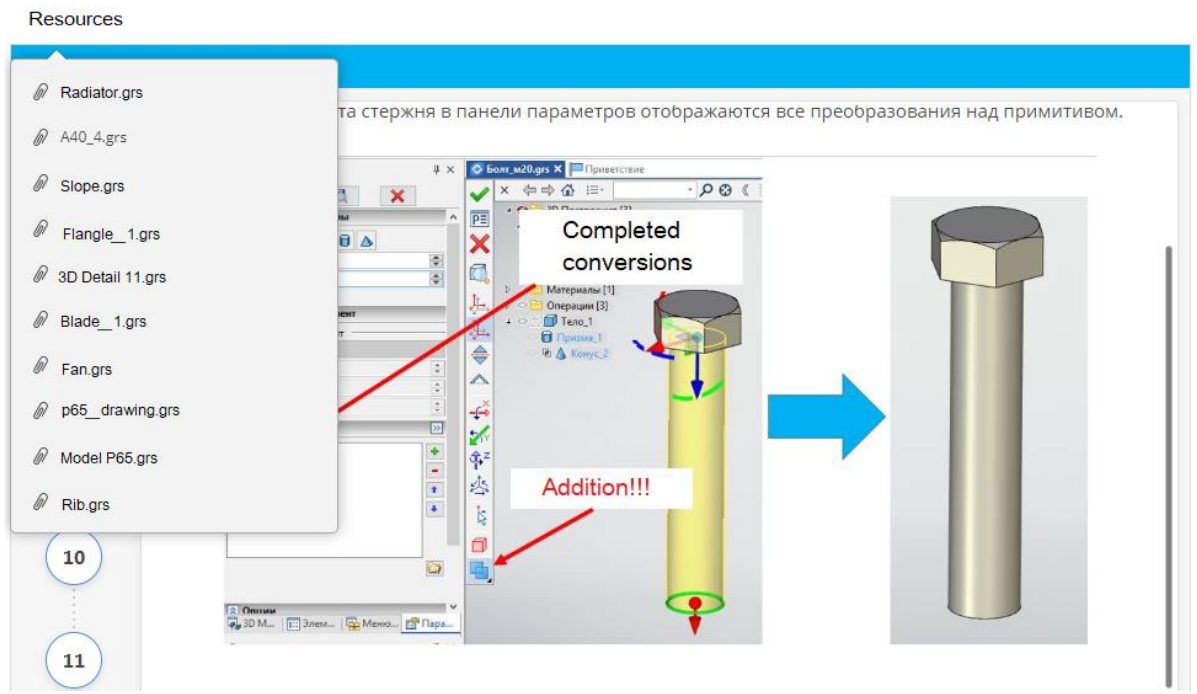

Fig. 11. 3D model blanks in course resources for developing 3-dimensional design skills.

Figure 11 shows a slide with a typical algorithm for building a 3-dimensional part (in this case, an M20 screw using templates). On the left side of the slide, there is a numeric scale for the operation number. In the center of the slide is a picture from the program 
interface with superimposed hints where to click. In addition, the slide is accompanied by an audio track describing the algorithm. After building the screw, on the last slide, a video sequence repeats all the operations performed.

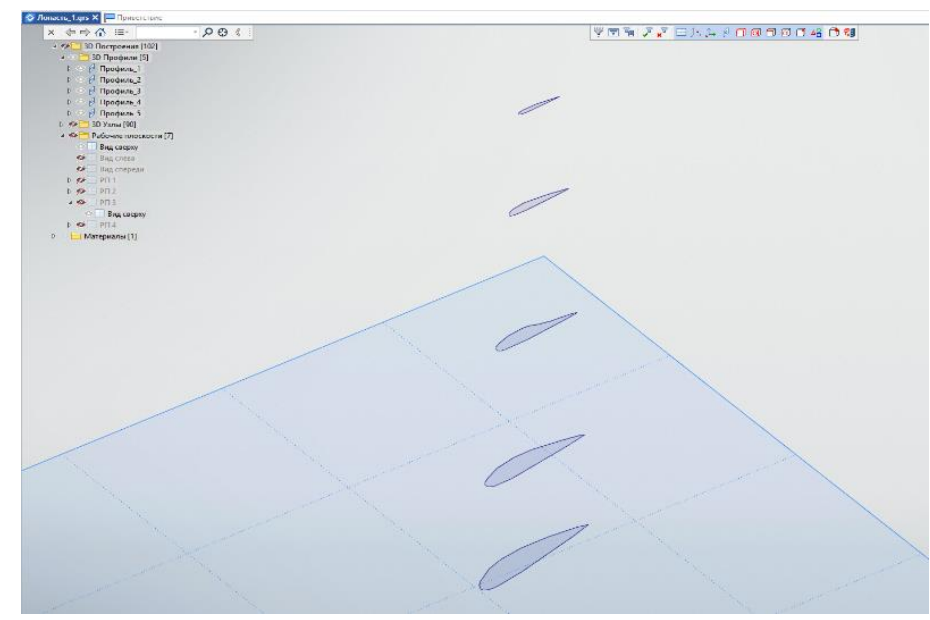

Fig. 12. "Blade_1" part from the ELC resources.

Module 7 "3D Assembly in T-FLEX-CAD" presents algorithms for creating readymade structures from an existing array of parts. This skill allows specialists to check the "collectability" of components and aggregates at the early stages of design, as well as to evaluate the manufacturability of the structure and its weight and size characteristics. The course offers two methods for creating an Assembly part: "binding via interfaces" and "binding via local coordinate systems". The first method is "classic" and is used in all CAD systems. The second method is extremely rare, but this method has a high stability of assemblies (which is important for a large number of parts) and low requirements for computer resources (since only coordinates are recalculated when the Assembly is rotated, and not the interaction of all interfaces).

The next topic "building a multiplier" is divided into two modules (the 8th and 9th) and is the final work that consolidates all the knowledge gained before. In this article, it is proposed to perform a 3-dimensional assembly process of a single- threaded straight-tooth multiplier with a transfer ratio of 1.8. The choice of the multiplier is justified by the fact that most of the wind power plants have a multiplier that connects the wind forest shaft with the electric generator. In addition, multipliers/reducers are used in control systems for azimuth and stepper drives of wind turbines.

A step-by-step procedure for performing operations is presented for building an assembly of an aggregate (see Fig. 13), as well as accompanying videos integrated into the course. All the parts needed to build the multiplier are available for download in the course resources. Initially, listeners are offered a list of necessary parts, an algorithm for assembling the shaft with a neck and bearings, and a method for installing the shaft in the housing. However, the shaft must rotate in the gearbox, so to implement this effect, the course describes in detail how to implement restrictions on degrees of freedom and movement using both slides and video clips (see Fig. 14). 


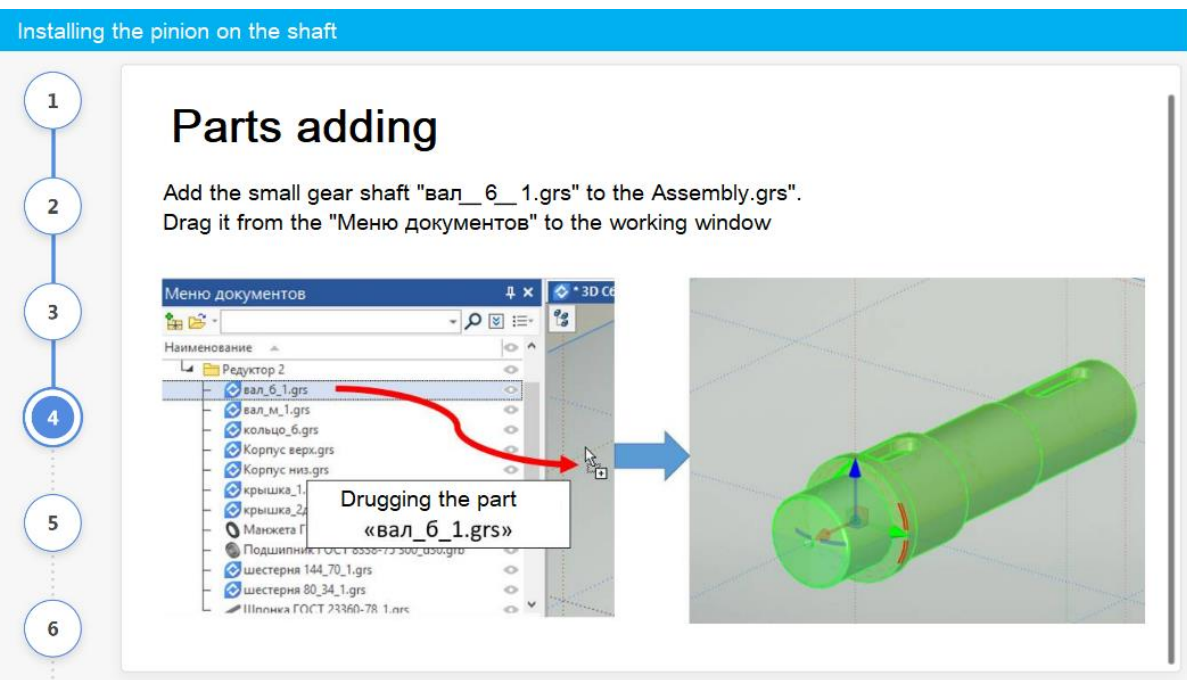

Fig. 13. Typical algorithm for adding a part to an assembly.

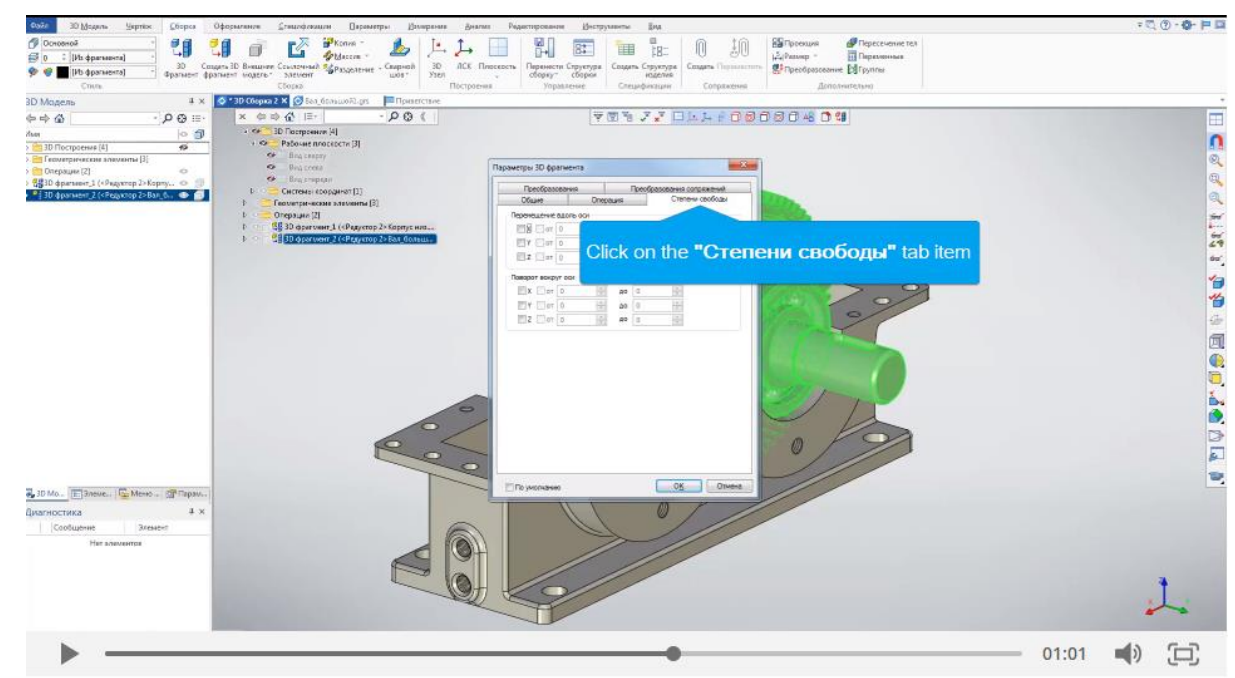

Fig. 14. Video clip with the implementation of the shaft rotation in the housing.

In addition, a whole block is devoted to checking the intersection of parts, as well as adding kinematic links that allow you to realize the correct rotation of the multiplier shafts. Fig. 15 shows the implementation of the "wheel (angular velocity)" interface. This allowing rotate one shaft to see how the second one rotates with the required gear ratio in the multiplier equal to 1.8 . 


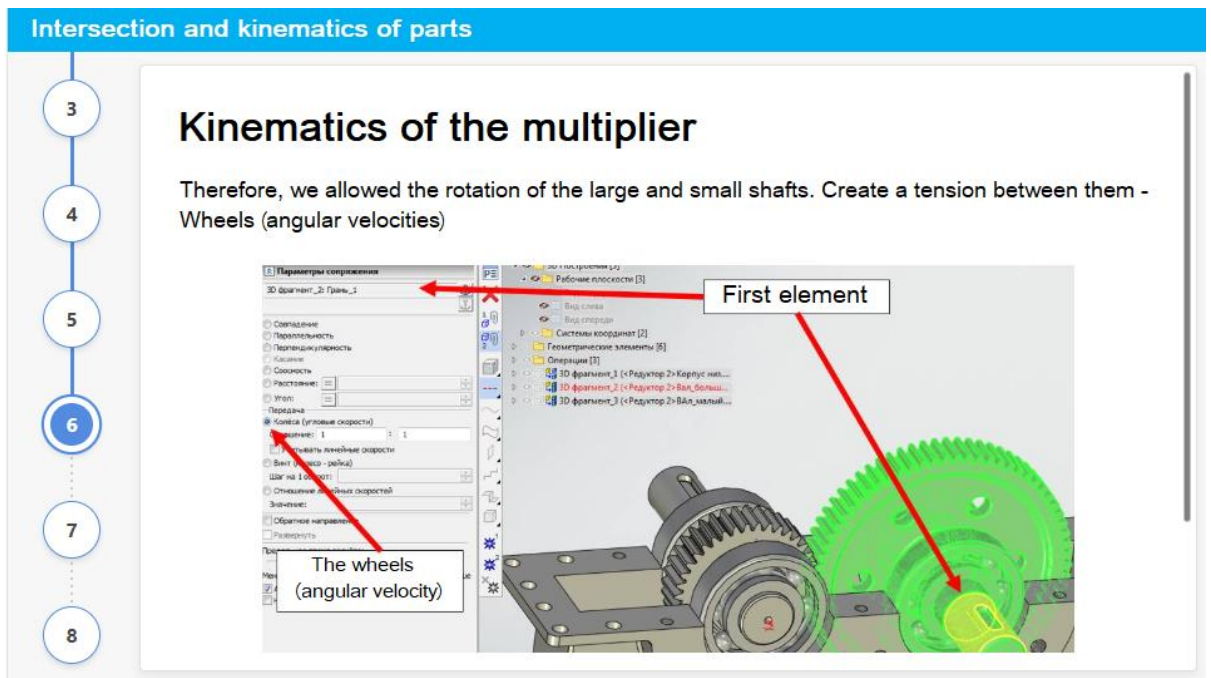

Fig. 15. Implementation of kinematic links in the multiplier.

Figure 16 shows the final form of the multiplier that students must collect at the end of the ninth module.

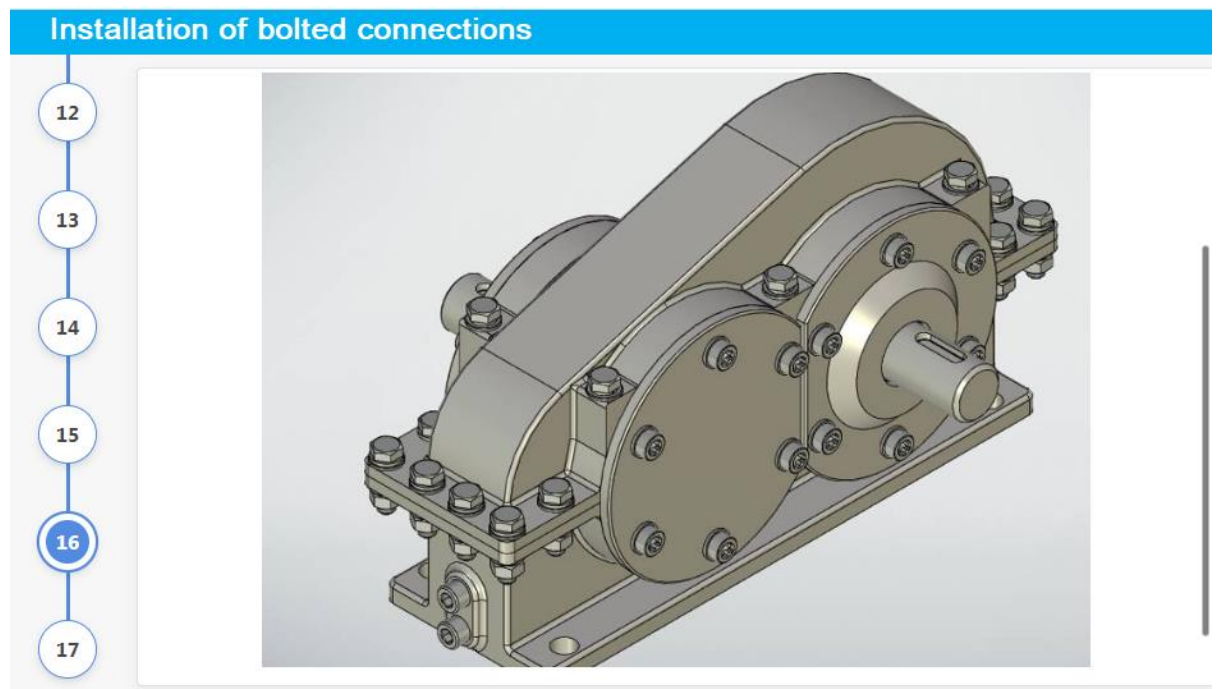

Fig. 16. Final view of the multiplier. 


\section{Multiplier assembling}

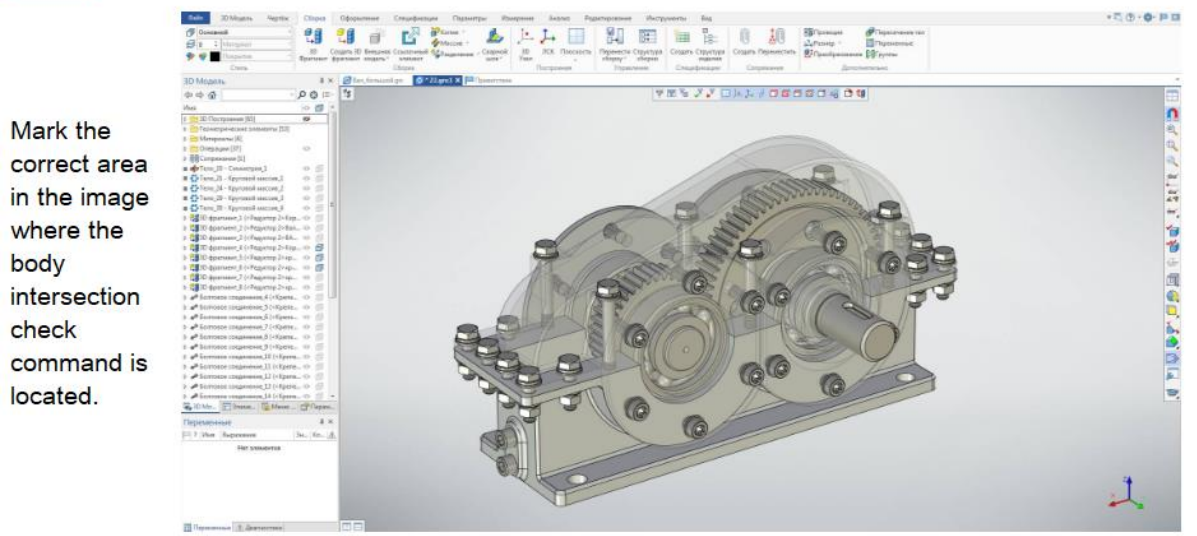

ANSWER

Fig. 17. The final test task.

At the end of the last module, the listener is waiting for a test (see Fig. 17), where it is necessary to mark the location areas of a team and select the correct algorithms for solving certain tasks.

\section{Conclusion}

Aspects of the use of wind power plants as part of power systems are considered, existing problems are described and solutions are shown.

Systems for developing e-learning courses and computer-aided design are presented. Based on the analysis, we selected the domestic (Russian) program for creating e-learning courses iSpring Suite, which has support for the SCORM 2004 format and broad opportunities for integration with office packages, and the program for automated design of T-FLEX CAD.

The structure of the e-learning course consisting of nine modules has been created. The first module is devoted to the main features and regularities of wind power plants. The second module provides an overview of the most common computer-aided design systems, their advantages and disadvantages. In the third and fourth modules, various algorithms for building sketches and two-dimensional drawings are considered. The fifth and sixth modules show existing operations and commands for creating three- dimensional parts from ready-made sketches, primitives, templates, etc. the Seventh module describes two approaches to creating Assembly units in T-FLEX CAD. In the eighth and ninth modules, an example of creating an Assembly unit - a multiplier from pre-prepared 3-dimensional parts (present in the course resources) is implemented.

All modules have sound, video clips, interactivity and end with control tasks. 


\section{References}

1. The Global Trends in Renewable Energy Investment 2018 report, published on April 5th by UN Environment, the Frankfurt School-UNEP Collaborating Centre, and Bloomberg New Energy Finance, p. 86 (2018)

2. Atlas of Renewable Energy Resources on the Territory of Russia, Scientific Publication, Ros. Khim.-Tekhnol. Univ. im. D.I. Mendeleeva, Moscow (2015)

3. Y.A. Fetisova, B.V. Ermolenko, G.V. Ermolenko, S.V. Kiseleva, Determining the parameters of Weibull function to estimate the wind power potential in conditions of limited source meteorological data, Thermal Engineering, Vol. 64, No. 4, pp. 251-257 (2017). DOI: 10.1134/S0040601517040036

4. S.A. Burtsev, A.S. Komshin, Challenges in Development of Wind Energy in Russia, 2019 International Conference on Industrial Engineering, Applications and Manufacturing (ICIEAM), IEEE, 18779348, p. 5 (2019). DOI: 10.1109/ICIEAM.2019.8743088

5. Renewables 2018 Global Status Report, REN21 Secretariat, p. 325 04-06-2018

6. Brian Snyder, Mark J. Kaiser, Ecological and economic cost-benefit analysis of offshore wind energy, Renewable Energy, Vol. 34, Iss. 6, pp. 1567-1578 (2009). DOI: 10.1016/j.renene.2008.11.015

7. L. Hirth, S. Müller, System-friendly wind power: How advanced wind turbine design can increase the economic value of electricity generated through wind power, Energy Economics, Vol. 56, pp. 51-63 (2016). DOI: 10.1016/j.eneco.2016.02.016

8. M. Zemamou, M. Aggour, A. Toumi, Review of savonius wind turbine design and performance, Energy Procedia, Vol. 141, pp. 383-388 (2017). DOI: 10.1016/j.egypro.2017.11.047

9. R. Whittlesey, Vertical Axis Wind Turbines: Farm and Turbine Design, Wind Energy Engineering. Academic Press, pp. 185-202 (2017). DOI: 10.1016/B978-0-12-8094518.00010-2

10. J.O. Dabiri, Potential order-of-magnitude enhancement of wind farm power density via counter-rotating vertical-axis wind turbine arrays, Journal of renewable and sustainable energy, Vol. 3, No. 4 (2011). 043104. DOI: 10.1063/1.3608170

11. R. May, et al., Considerations for upscaling individual effects of wind energy development towards population-level impacts on wildlife, Journal of environmental management, Vol. 230, pp. 84-93 (2019). DOI: 10.1016/j.jenvman.2018.09.062

12. R. May, et al., Future research directions to reconcile wind turbine-wildlife interactions, Wind Energy and Wildlife Interactions, Springer, Cham, pp. 255-276 (2017). DOI: 10.1007/978-3-319-51272-3_15

13. W.F. Frick, et al., Fatalities at wind turbines may threaten population viability of a migratory bat, Biological Conservation, Vol. 209, pp. 172-177 (2017). DOI: 10.1016/j.biocon.2017.02.023

14. T.E. Katzner, et al., Golden Eagle fatalities and the continental scale consequences of local wind-energy generation, Conservation Biology, Vol. 31, No. 2, pp. 406-415 (2017). DOI: $10.1111 /$ cobi.12836

15. M.W. Goodale, A. Milman, Cumulative adverse effects of offshore wind energy development on wildlife, Journal of Environmental Planning and Management, Vol. 59, No. 1, pp. 1-21 (2016). DOI: 10.1080/09640568.2014.973483 
16. A.I. Leontiev, et al., Experimental investigation of heat transfer and drag on surfaces coated with dimples of different shape, International Journal of Thermal Sciences, Vol. 118, pp. 152-167 (2017). DOI: 10.1016/j.ijthermalsci.2017.04.027

17. E. Metelkina, A. Komshin, The use of measuring phase-chronometric systems in the production of cyclic aggregates of aircraft, MATEC Web of Conferences. EDP Sciences, Vol. 129, 01048 (2017). DOI: 10.1051/matecconf/201712901048

18. I.K. Marchevsky, V.V. Puzikova, Numerical simulation of wind turbine rotors autorotation by using the modified LS-STAG immersed boundary method, International Journal of Rotating Machinery, Vol. 2017, ID 6418108, p. 7 (2017). DOI: $10.1155 / 2017 / 6418108$

19. I.K. Marchevskii, G.A. Shcheglov, On the dynamic stability of an elastically fixed high-drag airfoil under vortical parametric excitations, Mechanics of Solids, Vol. 51, No. 3, pp. 349-356 (2016). DOI: 10.3103/S0025654416030122

20. Y. Zhang, et al., Risk-Based Admissibility Analysis of Wind Power Integration into Power System With Energy Storage System, IEEE Access, Vol. 6, pp. 57400-57413 (2018). DOI: 10.1109/ACCESS.2018.2870736

21. R.F. Arritt, R.C. Dugan, Distribution System Analysis and the Future Smart Grid, IEEE Transactions on Industry Applications, Vol. 47, No. 6, pp. 2343-2350 (2011). DOI: 10.1109/TIA.2011.2168932

22. T.Yu. Tsibizova, Ye.V. Chernega \& O.M. Avgustan, Formation of information and educational environment for interaction between teachers and students (on the example of the "Technopark" project of BMSTU and Mail.ru Group), International journal of experimental education, (9), pp. 80-85 (2017)

23. F.R.P. Santos, I.A.S. Concilio \& J. Pessoa Filho, Development of Learning Objects for Teaching Mathematics using SCORM, 2018 XIII Latin American Conference on Learning Technologies (LACLO), pp. 264-269, October 2018, IEEE (2018)

24. E.V. Smirnova, A.A. Dobrjkov, A.P. Karpenko \& V.V. Syuzev, Mentally structured educational technology and engineers preparation quality management, Conference on Creativity in Intelligent Technologies and Data Science, September 2017, pp. 119-132, Springer, Cham (2017)

25. V. Guznenkov \& P. Zhurbenko, Electronic Geometric Modeling Is the Basis of Modern Geometric-Graphic Education in the Technical University, International Conference on Geometry and Graphics, August 2018, pp. 1268-1273, Springer, Cham (2018) 